seek out death. Aggin, when it is thought that a mere inspection of a body within twenty-four hours of the supposed death is sufficient to warrant a doctor in declaring life is extinot, ignorance of the difficulties in the determina tion of the presence of or absence of life can be the only excuse. In most cases a layman's testimony is sufficient, but in a few the task would test the best of us.

The demands of the bill have already been criticized, and now it may well be asked, How do you propose to carry ont the objects the promotors of the bill have at heart?

Now, given a local register in the bands of the medical officer of health, I would suggest the following :

1. When a death occurs the relatives to notify the police.

2 The police in case of a natural death to inform the doctor who was last in attendance.

3. The doctor, if he is satisfied, to sign a certificate and to give it to the police officer to take to the local medical officer of health's office, where it should, if in order, be registered.

4. The medical officer of health to grant a burial certificate and the police officer to convey it to the relatives. (In case the doctor declines, or there are some difficulties in the way of signatures, then the medical officer of health should prosecute inquiries and make or order to be made a proper medical examination of the body of the deceased.)

5. In case all be explainable by natural causes, the medical officer of health should then issue a burial certi. ficate; if no such explanation can be put forward, the medical officer of health should ask the coroner to undertake the necessary legal inquiry.

6. In all cases of accident, suicide, etc, the police officer to communicate direct with the coroner, who would cal for the services of the medical officer of health for the district to aid him in every way through his special medical officer to find out the cause or causes of death.

Sach is the ontline of the scheme I would advocate, and I venture to think that the objects of the promoters of the Coroners Bill would be attained in a far simpler and less costly way than that put for ward.

If, however, the State requires the application of a test as to whether a body is alive or dead, the State should be prepared to pay for the performance of an operation of skill, be it venesection or anything else, and the proper person to perform such is the general practitioner in attendance during the life of the deceased.

In conclusion, all I have to say is that those who are concerned in this matter should soon take steps to put into shape their own ideas and present them to the proper anthorities before the bill is again proceeded with, and so aroid increasing difficulties in obtaining amendments.

\section{THE PITFALLS OF "MENTAL TESTS." *}$$
\text { BY }
$$

CHARLES S. MYERS, M.D., Sc.D.,

LECTORER ON EXPERIMENTAL PSYCHOLOGY, UNIVERBITY OF CAMBRIDGE.

IN this country at least psychology seems likely to suffer from the same dangers of popularization as have for years past been affecting anthropology. Just as it has been widely supposed that only a printed book of instructions and queries need be read for an amateur to aally forth into the field and collect reliable physical measuremente, or trustworthy evidence of social organization, so there appears to be starting a belief that no special course of training is necessary in order to conduct on a large acale investigations of a psychological nature.

Folk are loth to recognize that the younger sciencesfor example, economics, genetics, psychology, educationdemand as much adequate preparution and study as the older before reliable work can be undertaken in their respective fields. Certainly every one thinks himself capable of discoursing and deciding about themes of psychological interest. Royal and Departmental Com missions, which do not contain among their members a single psychologist, are appointed to report on matters which are fundamentally of psychological concern. The psychologically untrained physician does not hesitate to

* A paper communicated to the British Association for the Advance ment of Science, at the Sheffield Meeting, 1910. pronounce on the psychology of insanity, nor the biologist on human and animal intelligence and instinck.

I want to protest as strongly as I can against the notion that any useral purpose can be eerved, so tar as psychology is concerned, by collecting masses of psjchological data with the help of an army of untrained observers. I have heard it confidently asserted that the gross errors inevitably arising from inaccuracies and inconsistencies of procedare among different observers cancel one another in the long run of such vast numbers of measuremente. Nothing, I tbink, can be more dangerous or false than this idea that the antrustworthiness of crude methods diminishes as the number of observers increasee. It involves the assumption that in the long run errors occur to an equal extent in opposite directior s-a most unlikely hypotbesis.

Individual differences in mode of measurement are great cnoggh even in anthropometry, despite the standardization of measurements. There is, I believe, a well founded rumour that when the pigmies visited this country and were independently measured by several observers well practised in anthropometry, the results obtained by these observers were startlingly divergent. If this be so, the sooner the fact is pat on record the better for the fature security of anthropometry. In any case I am sure that hitherto it has not been adequately realized how untrustworthy is a comparison between the measurements obtained by different observers upon the same individual. I can only give one or two actual examples, bat these, perhape, are snfficiently striking. Professor Cunningham and $\mathrm{Mr}$. Browne measured the hesds of several anatomists at a meeting of the Anatomical Society some years ago. One of their subjects gave a head length of $198 \mathrm{~mm}$. and a head breadth of $147 \mathrm{~mm}$. - that is, a cephalic index of 74.24 . The same individual happered to be measured sub. sequently by Miss Alice Lee, fully as competent an observer, who obtained a he ad length of $195 \mathrm{~mm}$. and a bead breadth of $150 \mathrm{~mm}$.- $1 \mathrm{hat}$ is, a cephalic index of 76.92. Thas there was a divergence of over 3.5 per cent. in the values of the index obtained from the same individual by these observer', although each claimed to be taking precisely the same measurements-the maximal head length and the maximal head breadtb.

A similar experience befell me only a short time ago. My head was measured by an observer who had for some months been engaged in making a vast collection of anthropometric data. He entered my head length as $202 \mathrm{~mm}$., my head breadth as $168 \mathrm{~mm}$. - that is to say, a cephalic index of 83.2 . Doubting whether these data were accurate, I took the calipers in my own hands and obtained a head length increased by $4 \mathrm{~mm}$. and a head breadth diminished by $2 \mathrm{~mm}$., yielding a cephalic index of 80.6. The latter I know to be approximately correct.

If inaccuracies to this extent occur when anthropometry is in the hands of fairly.trained observerp, what must be their size when the measurements are undertaken by the interested amatenr! And, if they are great in measuring the physical characters of man, what must they be in measuring the mental characters! For here we have not only the dangers arising from the improper use and reading of the instrument, bat also the different effects upon the subjects' mental condition produced by different observers. One observer knows his subjects well, another awes them by an unsympathetic attitude, while another unconsciously helps them by suggestion.

We have the farther difficalty that it is impossible as yet to standardize mental tests as we have standardized physical measuremente. Far more laboratory work is necessary before such fixity becomes possible or desirable. The approved test of to.day is rejected to.morrow.

But I will les,e thege difficulties on one side and pass on to the purposes of this wholesale application of "mental teste." One of the objects is to diecover by statistical means the differences which exist in different communities. A vast number of measurements of a given character is taken in one community and an equal numb: $r$ of messurements of the same character is taken in another. The averages of the two series are compared, and the conclusion is drawn that an undoubted, or a probable, or no certain difference exists between the two communities in respect of this character. As is well knowr, the certainty of the difference depends not only on the number 
of observations, but also on the relation between the amount of the difference and the uniformity of the individual measurements within either community. If the individual measurements within a community differ widely from one another, it is obvious that the difference between the averages must be proportionately wide, in order to be certain that it is not merely accidental. Now, so far as the physical measurements of mankind go, they do differ enormously within a given community. They differ so widely that it may be said that statistics can seldom give us any new information as regards racial differences of measurements. Statistics serve, as a rule, but to establish and to give a measure of observable differences. Statistics cannot inform you that one community has broader noses, darker skins, more curly hair, or greater stature than another, unless that character is manifest enough to be apparent to the non-statistical eye. And if this be true as regards physical charactere, it holds yet more strongly in respect of mental charactere, inasmuch as they exhibit still wider individual variation within a community. For these reasons we must be chary against expecting from statistical manipulations more striking results than from the very nature of the data they are capable of pielding.

I am fully aware that these opinions savour of hetero. doxy. I shall be asked, Are those not striking and new results which have been lately reached by statistical methods, showing the absence of correlation between the state of nutrition of school children and their mental capacity, or between alcoholism in the parent and defective health in the offspring? And I reply that, in my opinion, these results have no real value. They have been obtained by applying scientific methods to the solution of a problem of such complexity that the solution appears in the form of a meaningless blur.

The plain man believes that "One can prove anything by statistice," and I fear that such time-worn saying have a certain basis of trath. For the wholesale collectors of measurements are apt to pay too little regard to the complexity of the conditions influencing the problem and the material which they are gathering. All they desire is an enormous mass of data, and these-good, bad, com. parable, and non-comparable-they pour into the statis tical mill with the object and result of arriving at con. clusions statistically invulnerable. Into this mill, for instance, they pour all the data concerning the relative efficiency, physical and mental, of the children of drunken and sober parents, practically regardless of the question as to whether the parents are strong, robust folk who are abstemious, or, say every Saturday night, regularly indulge in intoxication, or whether they are feeble workmen of the sober "good young man" type, or weakly degenerates, inheriting and transmitting disorders of nervous instability so closely associated with tendencies to crime and to chronic alcoholism.

Similarly, in dealing with the relation of mental capacity to bodily nutrition among children, a recent investigator has been content to take the verdict of school teachers on the mental capacity of their school children, with the result that some teachers classified 33 per cent., others only 1 per cent., of the children as brilliant! On the ground that the ablest parents can provide the best nutrition and transmit their ability to their children, it might be argued a priori that dull children would not be so well nourished as bright children. And this conjecture is supported by earlier trustworthy evidence. On the other hand, its raison d'être can only hold for the lower and lower middle classes, and we have the further complication that un wholesome food may produce a false appearance of good nutrition. Apart from food supply, exceptionally brigh children are worse nourished, and exceptionally dull children are better nourished, than the average child. These complications should no doubt be taken into con. sideration, as should such factors as employment outside school hours and the mental and physical condition of the parents. When all these counteracting influences are thrown into the statistical melting pot, is it surprising that the result is a mere blur, showing an absence of significant correlation, a small correlation in one direction in one school and in an inverse direction in another?

This neglect to analyse and to take heed of what is actually being measured is specially prone to occur in the use of mental tests. In other sciences there is little or no real difficulty in observing what we are measuring, if only the experimenter take reasonable care. But in psychology we can only ascertain what we are testing by recourse to introspection on the part of the subject. To neglect introspection in psychological experiment is usually to court certain disaster. If we are in total ignorance of what has been going on in the mind of the subject during the experiment, it is rarely possible to argue from the objective [data-from the measurements which it yields. For example, we may be trying to determine whether any correlation exists between sensory discrimination and general intelligence. A positive result may be simply due to the fact that the very nature of the test has compelled the subject to use his intelligence while carrying out sensory discriminations. We may be correlating mental ability with mental fatigue, and neglect the fact that sometimes we may not be measuring fatigue at all, that in some subjects the task becomes automatic, in others tedious, or that boredom may be in others overcome by motives of duty or ambition. We may be testing the visual acuity of two persons and obtain a different result from each, despite the fact that really they have the same visual acuity. The result may be due to the fact that the one subject strains every effort to interpret what he bat dimly sees, while the other only reads what he believes he can clearly see. Thus again we merely obtain a blurred cr erroneous result from the blind applications of statistical methods to measurements which are really meaningless owing to our failure to analyse the conditions determining the character we are measuring.

The danger of drawing conclusions from too small a number of subjects is well illustrated in the results of an inquiry recently conducted into the correlation between ability in mathematics and ability in classics in the various forms of a public school. In the highest form, the correlation was found to be +0.20 ; but in the following year in the same form it amounted to +0.52 . In the form below it was +0.23 , in the next lower form +0.76 , and in the next -0.25 .

But there is likewise a pitfall from the use of a large number of subjects, and this $I$ will illustrate, as before, by analogy from physical anthropology. It is obvious that if you determine the correlation between head length and head breadth for one race or for one ethnic element of a mixed people-for example, the Cornishman in our own country-we shall find this correlation to be quite different from that obtained from another race or for another ethnic element of a mixed people - for example, the East Anglian. There can be no question about the existence of similar diff. culties with regard to the correlation of mental characters. How wide the racial differences are in the correlation of mental characters is, of course, unknown. But no doubt at one time in a given class or school of our beterogeneous popalation the ethnic diversity may be small, at another time it may be great. At one time one racial element may preponderate, at another time another. This possibly is one explanation of the marked discrepancies obtained by different observers and by the same observer at different times, using the same mental tests as far as possible in the same manner. It provides yet another confirmation of $\mathrm{my}$ thesis that the wholesale collection of measurement is apt to give us only a very blarred and often a very inaccurate picture of the factors which really underlie the problem under investigation. It fails to give results of psychological value, because the psychological standpoint, the experience of the individual, is neglected. It is only too apt to obscure actual correlations or to reveal spurious correlation becanse insufficient care is taken to analyse the conditions which are really at work during the experiments. It leads to inaccurate results owing to the errors arising from individual differences in applying the tests.

For these reasons I arge extreme caution, at least for the present, in standardizing "mental tests" and in popularizing their use. In some forms, no doubt, tests can be usetully applied en masse-for example, with the object of determining the standard of intellect which a boy of given age should attain in order to class him as suitable or unsuitable to be taught in an "ordinary" or a "special" school. But such tests are "tests of pro. 
duction," not " mental tests." They determine how much an individual can work, how much he knows-not how he works, how he knows. A man's productivity, of course, is what we want to ascertain in everyday life. We do not care how a man comes to use or to acquire his powers we are content with a mere dynamometric or other record of his prowess. From this aspect, mass experiments must have some value. But this aspect cannot properly be called the psychological aspect.

\section{Ettemuranda: \\ MEDICAL, SURGICAL, OBSTETRICAL.}

A CASE OF URAEMIC APHASIA.

ON January 13th I saw, in consultation with Mr. J. H. Blakeney, of Cheltenham, a gentleman, aged 53, who had been seized on the previous day with loss of the power of speech; when I visited him, this had passed off, and only a little slowness in articulation was noticeable. There was no loss of power on the right side, and the plantar reflex of the right foot was flexor. The knee-jerks on both sides were exaggerated. His pulse was hard; the apex beat was not displaced; urine 1014, acid, haze of albumen, no sugar, deposited a few slender granular casts; ejesight normal. He was well developed, sparely nourished, but muscular ; not cachectic-looking, and had been a great athlete.

The history was that at the age of 20 he had an attack of acute nephritis; he was ill six weeks, but was supposed to have made a good recovery. Fifteen years ago, how. ever, he was rejected for life insurance on account of the presence of albumen in the urine, and he had had frecpuent attacks of gout during the last fifteen years. He had a profuse epistaxis eleven years ago. In May, 1909, he was ound standing by his dressing.table unable to speak; he vomited and was pat to bed; there was no definite hemiplegia, but he said afterwards that his right hand felt numb. He recovered in about a fortnight, but has never since resumed his occupation. In July he had an attack of convulsions, after which he was unconscious for twelve hours. In September he had his second attack of aphasia, with a slight loss of consciousness, lasting for a few hours. Later in the same month he had two attacks of convalsions followed by unconsciousness and violent delirium. In March, 1910, an attack of aphasia with slight un consciousness was followed by delirium and mental symptoms which lasted six weeks. In September he had another attack of aphasia; in November his pulse became very slow, the rate falling to 26. Early in December there was a slight aphasic attack, and on January 12th of this year another for which I saw him.

Although transient aphasia is mentioned in most textbooks as one of the phenomena occasionally observed in ursemia, it is sufficiently rare to justify me in asking per mission to publish these brief notes. Few cases are to be found in looking up standard writers on Bright's disease but one was published by the late Sir T. Grainger Stewart, in which transient aphasia was associated with facial paralysis and some weakness of the right arm, and there is another in Dr. Samuel West's Lettsomian Lectures (p. 139), in which the patient had recurrent attacks of right hemiplegia with aphasia extending over eight years: there was no albuminuria, but the arteries were thickened, and there were "two small patches of degeneration of the ordinary kind in the right eye." In Mr. Blakeney's case there is no doubt of the presence of chronic renal disease the uraemia associated is attested by the oceurrence of convulsive attacks, and it is noteworthy that the aphasia was not attended by hemiplegia.

Birmingham.

Robert SaUndey, M.D., F.R.C.P.

TREATMENT OF PERNICIOUS MALARIAL FEVER IT is well known that red blood corpuscles containing malarial parasites are more easily disintegrated thar normal non-infected blood cells. This gives us a clue to the treatment of pernicious cases of ferer which one comes across now and again in the tropics, and which are almost invariably so fatal. I refer more particularly to

1 Clinical Lectures on Important Symptoms, Fasciculus II on Albuminuria, p. 107. cases of the comatose type, resembling in many aspects a bacterial meningitis. These cases present a profound toxaemia associated pathologically with a conglomeration of infected erythrocytes in the cerebral capillaries.

Rogers has been showing for the past two years the value of hypertonic saline solution in cholera. In the treatment of severe malarial conditions we desire, if possible, to produce sn effect of another kind, although also by a temporary alteration in the saline content of the plasma. It is one in which the blood plasma is more diluted, giving those red blood corpuscles which are infected a greater opportunity of disintegrating and allowing quinine to act more immediately on the malarial organism.

This can be done by the transfusion of a "hypotonic" saline solution (30 grains to 1 pint). The osmotic pressure within the red blood corpuscles, if the injection has been carried out at the rate of quite 20 ounces in ten minutes, becomes relatively a negative one, and to a certain extent it is selective in that it is accumulative in affecting more readily those cells whose resistive powers have already been weakened by being organismally infected. To take advantage of this alteration it is of course necessary that the patient's circulation contain an effective amount of quinine ready to deal with the organisms, possibly nascent in the plasma, or at any rate more easily reached in the intracellular osmotic ebb and flow. To get this $\epsilon$ ffect it must be borne in mind that rapid introduction of hypotonic saline is necessary, as interaction with the tissue fluids in a very short time diminishes the positive osmotic pressure of the surrounding plasma with regard to the corpuscles pari passu with its saline content quickly reapproaching the normal limit, which, considering the amount of blood in the body, can only have tended to produce the laking effect to a small extent.

Although it is unlikely that much actual laking takes place, even in infected erythrocytes, still the very change $\$$ occurring in the tension of the plasma must react on the corpuscles, and involve interchange of fluids, which, containing even minute percentages of quinine, must have an effect the reverse of salutary for the invading haemosporidia.

Gyantse, Thibet.

$$
\text { D. M. C. Chorch, }
$$

$$
\text { Captain, I.M.S. }
$$

CONGENITAL ABSENCE OF ONE KIDNEY. ThE extreme rarity of the anatomical condition found in the following case demands in the interests of the profession a brief record.

A. E. S., a married woman, aged 58, was found drowned in the Regent's Canal on December 3rd, 1910. The post. mortem examination was made on December 6th. The body was well nourished; neither the loin nor the anterior abdominal wall presented any scar externally. On opening the abdomen there was observed on the right side, and covered by the bowels, a large swelling. This was found to be the right kidney in its normal position. It weighed $11 \mathrm{oz}$; the vessels were large and engorged with dark fluid blood; the ureter was slightly larger than normal. From a naked eye inspection the condition of the kidney appered one of simple hyperplasia. On looking for the left kidney it was nowhere to be seen. There was a flatness of the posterior wall of the abdomen instead of the usual hollow. There were no left renal vessels, no left ureter, and no trace of embryonic remains. The left crus, quadratus, and psoas stood out with no vestige of organ or tissue where the kidney should have been; the left suprarenal was absent. The bladder was normal, but had only one ureteric orifice-namely, that on the right side. The uterus was lying well over towards the right side, with a normal broad ligament attached thereto. On the left side, however, there was a large space which the fist easily occupied. The broad ligament on this side was represented by a narrow fold dipping down deep into the pelvis and rising again, the left ovary being almost on a level with the brim. There were no abnormalities of vulva, vagina, or uterus. The woman had had two children, both of whom are living.

My best thanks are due to Mr. T. W. P. Lawrence, curator, University College Hospital, who, in the presence of two of the visiting staff; laid open the bladder and exposed the single ureteric orifice. 